\title{
Clinical and Immunological Consequences of Human T Cell Leukemia Virus Type-I and Schistosoma mansoni Co-infection
}

\author{
Silvane Braga Santos/*, Aurélia Fonseca Porto, André Luiz Muniz, Amélia Ribeiro de Jesus, \\ Edgar M Carvalho/**/+
}

\begin{abstract}
Serviço de Imunologia, Hospital Universitário Professor Edgard Santos, Universidade Federal da Bahia, Rua João das Botas s/n, 40110-160 Salvador, BA, Brasil *Departamento de Ciências Biológicas, Universidade Estadual de Feira de Santana, Feira de Santana, BA, Brasil **Instituto de Investigação em Imunologia, São Paulo, SP, Brasil
\end{abstract}

\begin{abstract}
Human T cell leukemia virus type-I (HTLV-I) infection is associated with spontaneous $T$ cell activation and uncontrolled lymphocyte proliferation. An exacerbated type-1 immune response with production of pro-inflammatory cytokines (interferon- $\gamma$ and tumor necrosis factor- $\alpha$ ) is significantly higher in patients with myelopathy associated to HTLV-I than in HTLV-I asymptomatic carriers. In contrast with HTLV-I, a chronic Schistosoma mansoni infection is associated with a type-2 immune response with high levels of interleukin (IL-4, IL-5, and IL-10) and low levels of IFN- $\gamma$. In this study, clinical and immunological consequences of the HTLV-I and S. mansoni infection were evaluated. The immune response in patients with schistosomiasis co-infected with HTLV-I showed low levels of IL-5 $(p<0.05)$ in peripheral blood mononuclear cells cultures stimulated with $\mathrm{S}$. mansoni antigen $(S W A P)$ and decreased SWAP-specific IgE levels when compared with patients with only schistosomiasis ( $p<0.05)$. Liver fibrosis was mild in all HTLV-I co-infected patients. Immunological response was also compared in individuals who had only HTLV-I infection with those who were co-infected with HTLV-I and helminths (S. mansoni and Strongyloides stercoralis). In patients HTLV-I positive co-infected with helminths the IFN- $\gamma$ levels were lower than in individuals who had only HTLV-I. Moreover, there were fewer cells expressing IFN- $\gamma$ and more cells expressing IL-10 in individuals co-infected with HTLV-I and helminths. These dates indicate that HTLV-I infection decrease type 2-response and $I g E$ synthesis and are inversely associated with the development of liver fibrosis. Moreover, helminths may protect HTLV-I infected patients to produce large quantities of pro-inflammatory cytokines such as IFN- $\gamma$.
\end{abstract}

Key words: human T cell leukemia virus type-1 - Schistoma mansoni - co-infection

The human T cell leukemia virus type-I (HTLV-I) is an oncogenic exogenous retrovirus that infects between 10 and 20 million people worldwide (Edlich et al. 2000). HTLVI is the recognized cause of adult T-cell leukemia (ATL) as well as HTLV-I-associated myelopathy/tropical spastic paraparesis (HAM/TSP) (Osame et al. 1986, Uchiyama 1997), but other disorders have been associated with HTLV-I infection. The immunological response in HTLV-I infection is characterized by a spontaneous lymphoproliferation and an exaggerated $\mathrm{T}$ cell response with high production of important inflammatory mediators of tissue damage as interferon- $\gamma$ (IFN- $\gamma$ ), tumor necrosis factor- $\alpha$ (TNF- $\alpha$ ) and interleukin (IL-6) (Nishimoto et al. 1990, Kubota et al. 1998, Carvalho et al. 2001). Although the pathogenesis of neurological disease associated to HTLVI is not completely understood, there are various evidences that immunological response participate and is responsible by inducing tissue damage (Hanon et al. 2000, Nagai \& Jacobson 2001, Osame 2002). By the other hand, helminthes infections such as strongyloidiasis and in

Financial support: Brazilian Research Council, Fundação de Amparo à Pesquisa do Estado da Bahia

+Corresponding author and CNPq Senior Investigator. Fax: +5571-245.7110.E-mail:imuno@ufba.br.

Received 28 May 2004

Accepted 26 July 2004 particular a chronic disease caused by infection with Schistosoma mansoni are associated with a predominant antiinflammatory type- 2 immune response with increased levels of IL-4, IL-5 and IL-10 and low levels of IFN- $\gamma$ (Araujo et al. 1996, Finkelman et al. 1997). The high degree of infection and the host's immune reaction to parasite eggs contribute to granuloma formation. Liver fibrosis is the most important pathological finding in schistosomiasis, being registered in about $5 \%$ of chronically $S$. mansoni infected patients (Bina \& Prata 2003). Although initial experimental studies suggested that type-1 cytokines were associated with granulomatous reaction to $S$. mansoni infection (Leptak \& McKerrow 1997, Rezende et al. 1997), its clear from current data that type-2 cytokines play a primary role in inducing fibrosis, whereas the IFN- $\gamma$ (type1 cytokine) acts as an endogenous down regulator of the response (Wynn et al. 1994, Chiaramonte et al. 1999a, Jankovic et al. 1999). Simultaneous infection between HTLV-I and Strongyloides stercoralis decreases the predominant type-2 immune response in patients with strongyloidiasis (Neva et al. 1998, Porto et al. 2001a) as well as S. stercoralis-specific and total IgE antibodies (Neva et al. 1998, Porto et al. 2001b). Moreover, co-infection with HTLV-I is also associated with disseminated and recurrent strongyloidiais (Phelps et al. 1991, Newton et al. 1992). It is known that the prevalence of strongyloidiasis is higher in HTLV-I infected patients than in seronegative controls (Robinson et al. 1994, Hayashi et al. 1997). Based on these observations one of the aims of this study was to determine if HTLV-I infection decrease the type-2 im- 
mune response observed in patients with schistosomiasis and the impact of HTLV-I on the development of liver fibrosis. Moreover, considering that pathogenesis of diseases associated to HTLV-I is dependent of high production of pro-inflammatory cytokines it was evaluated if coinfection with S. mansoni and HTLV-I decrease the type1 immune response

\section{MATERIALS AND METHODS}

Patients' selection - Patients were selected from the HTLV-I clinic of the Hospital Universitário Professor Edgard Santos, Federal University of Bahia, Brazil. The clinic follows more than 500 HTLV-I infected individuals, most of then referred from two blood banks in Salvador, the capital of the state of Bahia. The diagnosis of HTLV-I infection was confirmed by Western blot (HTLV blot 2.4, Genelabs, Singapore). All patients admitted in the HTLVI clinic are asked to perform three stool examinations. From 500 HTLV-I infected individuals, 309 had stool examination. Frequency of $S$. mansoni infection was assayed in 309 HTLV-I positive individuals and 331 seronegative blood donors were screened as negative controls also by stool examination; 14 HTLV-I positive patients had $S$. stercoralis larvae in their stool examination and all of them participated of the study. S. mansoni eggs were found in 26 HTLV-I infected individuals, but only 22 of them accepted to participate in the study. The diagnosis of schistosomiasis was made by a positive fecal examination for eggs by Hoffman technique and the criterion for a diagnosis of strongyloidiasis was a positive fecal examination for larvae by the Baermann concentration technique. Fortyfour $(\mathrm{n}=44)$ patients with $S$. mansoni without HTLV-I infection were selected from an existing cohort of patients from an area endemic for $S$. mansoni infection (Caatinga do Moura, Bahia). These patients were used to select a ratio of 2 to 1 by matching age and sex with the group of patients with co-infection. Clinical history and a complete physical examination and abdominal ultrasound were performed in both groups with $S$. mansoni infection (HTLV- I positive and negative).

Neurological exam - Motor dysfunction was determined by Osame's Motor Disability Score (OMDS) (Izumo et al. 1996) and Expanded Disability Status Scale (EDSS) (Kurtzke 1983). Patients with HAM/TSP had a marked neurological impairment with EDSS $\geq 3$ and OMDS $\geq 1$ and all asymptomatic subjects had OMDS and EDSS of zero. Based on exclusion criteria that included the use of antiviral drugs or immunomodulators in the previous 90 days, co-infection with HIV, HCV or hepatitis B and presence of helminthes infection or other neurological diseases, 17 patients with HAM/TSP performed immunological evaluation. Thirty-six HTLV-I asymptomatic carriers, without clinical manifestations associated with HTLV-I were also selected. Healthy University Hospital employees who were seronegative for HTLV-I and seronegative normal donors without helminthes infection were used as negative controls.

The Ethical Committee of the Hospital Universitário Professor Edgard Santos approved this study and informed consent was obtained from all prospectively enrolled patients.
Cell preparation and cytokine determination - Peripheral blood mononuclear cells (PBMC) were obtained by density gradient centrifugation using lymphocyte separation media (LSM; Organon Teknika Coorporation, Durham, NS, US). PBMC were cultivated in RPMI 1640 (Gibco, Grand Island, NY, US) plus 10\% heat inactivated human AB Rh+ serum (Sigma Chemical Co., St. Louis, MO), antibiotics and glutamine (complete media) and adjusted to $3 \times 10^{6}$ cells $/ \mathrm{ml}$ in complete media. The cells were cultured unstimulated or stimulated with $2 \mathrm{mg} / \mathrm{ml}$ soluble adult S. mansoni worm antigen (SWAP) when patients were co-infected with $S$. mansoni. All cultures were incubated at $37^{\circ} \mathrm{C}$ in $5 \% \mathrm{CO}_{2}$ atmosphere for $72 \mathrm{~h}$ until supernatant fluids were collected. IFN- $\gamma$ and IL-5 levels were measured by sandwich ELISA technique (R\&D system, Minneapolis, $\mathrm{MN}$ ) and the results were expressed as $\mathrm{pg} / \mathrm{ml}$ using a standard curve generated using recombinant cytokines.

Flow cytometric analysis (FACS) - FACS was performed after $20 \mathrm{~h}$ of incubation. Briefly, the PBMC were immunophenotyped by double immunofluorescence using a FACScalibor flow cytometer and a panel of phycoerythrin (PE)-conjugated monoclonal antibodies. In all cases the cells were double stained for cytokine and for cell surface markers. Specifically the total percentage of cells producing IFN- $\gamma$ and IL-10 was assayed. In all cases, 30,000 gates events were acquired for later analysis due to the low frequency of positive events being analyzed.

IgE specific to S. mansoni antigen - Analysis of IgE specific to SWAP was performed by ELISA as previously described (Souza-Atta et al. 1999). The ELISA was developed with $100 \mu$ l of p-nitrophenyl phosphate and the absorbance changes (optical density, OD) were measured by a spectrophotometer at $405 \mathrm{~nm}$. The cut-offs of the immunoassay were determined using the mean plus $3 \mathrm{SD}$ of the absorbance obtained with serum from 15 healthy individuals.

Ultrasonography - Ultrasonography examination was performed with the Quantum 2000 Siemens ultrasound with a convex transductor of $3.5 \mathrm{Mhz}$, according to a previously published technique (Abdel-Wahab et al. 1992). Grading of hepatic fibrosis was determined according with WHO criteria established in 1993 and previously revalidated (de Jesus et al. 2000). Patients were classified in four different degrees according to the mean thickness of four portal tracts after the first division from the right and left branches of portal vein.

Statistical analysis - A non-parametric Mann-Whitney U Test was used to evaluate differences among the groups. Fisher's exact test was used to compare proportions. These statistical analyses were performed using the program Instat for Windows. An alpha $(\alpha)$ of $5 \%$ was considered significant.

\section{RESULTS}

To determine if HAM/TSP patients and asymptomatic subjects produce different levels of IFN- $\gamma$, this cytokine was measured in supernatants of unstimulated cultures of HTLV-I infected groups and compared with negative controls. There was a high variability in IFN- $\gamma$ levels in asymptomatic carriers (Fig. 1). The mean and SD of IFN- $\gamma$ 
levels in 17 myelopathy patients $(4,246 \pm 2,924 \mathrm{pg} / \mathrm{ml}$, range: 375 to 10,750 ), was higher than that observed in 36 asymptomatic carriers $(1,362 \pm 1,408 \mathrm{pg} / \mathrm{ml}$ range: 15 to $6,995)$ or in 15 negative controls $(1 \pm 4 \mathrm{pg} / \mathrm{ml}), p=0.0001$, Mann-Whitney $\mathrm{U}$ test. Evaluation of the frequency of helminthes infection in 309 HTLV-I infected subjects revealed that $S$. mansoni infection was 4.6 fold higher in HTLV-I infected individuals (26/309-8.4\%) than a comparable group of HTLV-I seronegative individuals (6/331 $-1.8 \%, \mathrm{p}=0.0003$, Fisher's exact test; data not shown). With the aim to evaluate whether HTLV-I infection modify the immune response in patients with S. mansoni, the levels of IL-5 in co-infected patients were measured and compared with IL-5 levels found in controls patients (schistosomiasis without HTLV-I infection) from an endemic area of $S$. mansoni infection. The mean \pm SD of IL-5 levels in patients co-infected with $S$. mansoni and HTLV-1 was 258 $\pm 692 \mathrm{pg} / \mathrm{ml}$ with variation of $0-2943 \mathrm{pg} / \mathrm{ml}$. This value was lower than ( $\mathrm{p}<0.05$, Mann-Whitney U test) that observed in patients only infected with $S$. mansoni $(907 \pm$ $1289 \mathrm{pg} / \mathrm{ml}$ with ranging of $0-4747 \mathrm{pg} / \mathrm{ml}$ (Fig. 2).

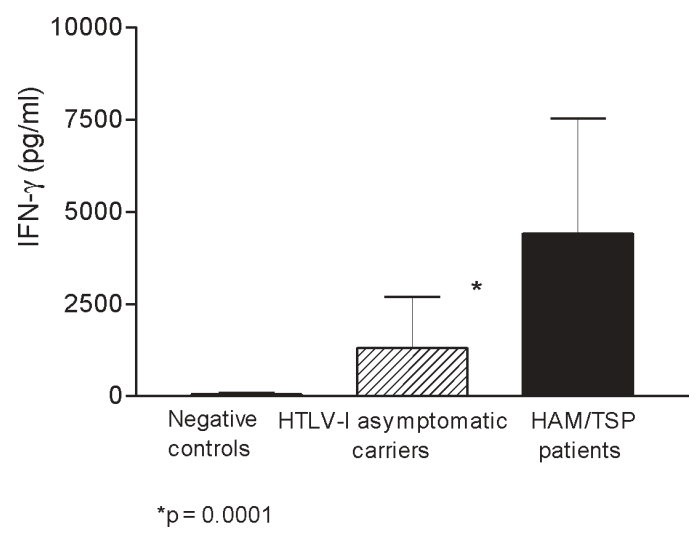

Fig. 1: interferon- $\gamma($ IFN- $\gamma$ ) levels $(\mathrm{pg} / \mathrm{ml})$ in HTLV-I-associated myelopathy/tropical spastic paraparesis $(\mathrm{HAM} / \mathrm{TSP})(\mathrm{n}=17) \mathrm{pa}-$ tients compared with asymptomatic carries $(n=36)$ and negative controls $(n=15)$. The bars represent the median of IFN- $\gamma$ concentrations and the difference were considered significant when $p<$ 0.05 (Mann-Whitney U Test).

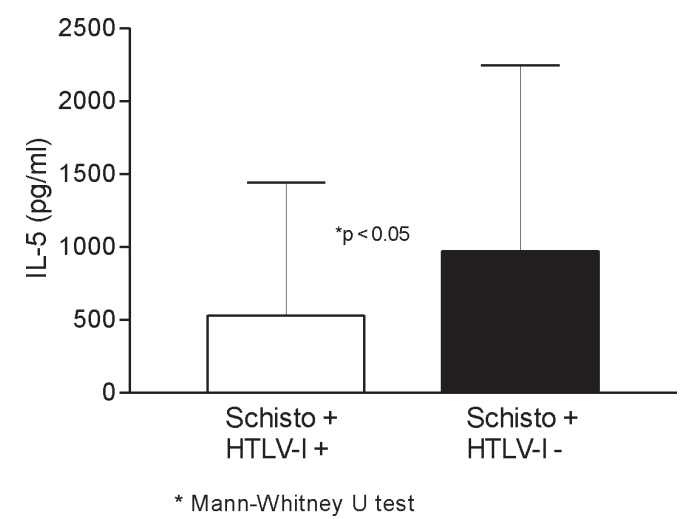

Fig. 2: HTLV-I down regulates IL-5 production to Schistosoma mansoni antigen. IL-5 levels in peripheral blood mononuclear cells stimulated with SWAP in S. mansoni and HTLV-1 co-infected patients $(n=22)$ and in chronic schistosomiasis patients $(n=44)$ from an endemic area.
To evaluate the role of HTLV-I infection on antigenspecific IgE levels in patients with schistosomiasis, the distribution of the $\operatorname{IgE}$, expressed in OD, in patients with schistosomiasis without HTLV-I infection and in those co-infected with HTLV-I was assayed (Fig. 3). The mean $\mathrm{IgE}$ in 40 patients without HTLV-I infection was $0.195+$ 0.169 compared to $0.123+0.04$ in 22 patients with schistosomiasis associated with HTLV-I infection $(\mathrm{p}<0.01$, Mann Whitney U test).

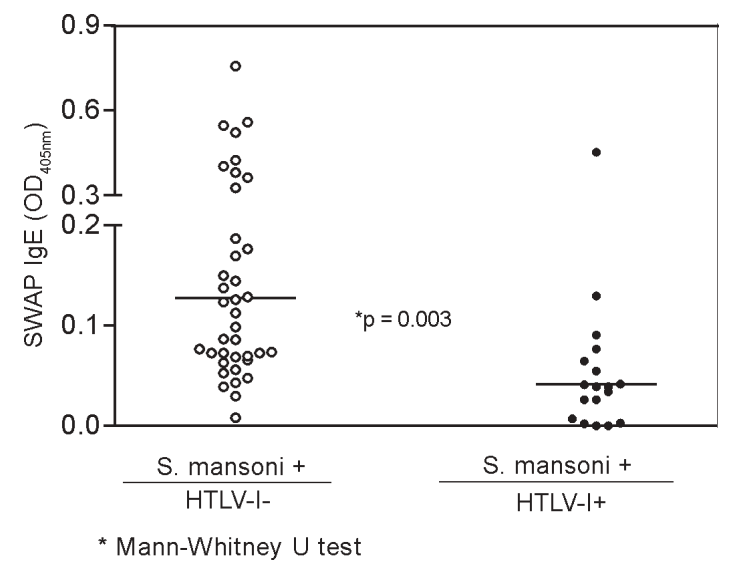

Fig. 3: SWAP-specific IgE from patients with Schistosoma mansoni infection $(\mathrm{n}=40)$ and $S$. mansoni co-infected with HTLV-I $(\mathrm{n}=$ 22).

Ultrasonography studies were used to further quantify the observed clinical findings. The ultrasound findings of 22 schistosomiasis patients co-infected with HTLVI and 40 schistosomiasis HTLV-I-seronegative controls are shown in the Table. None of the 22 co-infected patients had splenomegaly $(0 / 22)$, an index of severe hepatic fibrosis. Only one case had mild hepatomegaly (1/22). In contrast, age and sex-matched control schistosomiasis HTLV-1-seronegative cases showed a significantly higher frequency of clinical parameters for hepatic fibrosis. Splenomegaly was observed in $2.5 \%(1 / 40)$ and hepatomegaly was registered in 22\% (9/40) of the HTLV-I-seronegative schistosomiasis controls from Caatinga do Moura. An absence of or a mild degree of fibrosis was noted in 21 schistosomiasis patients co-infected with HTLV-I studied by ultrasound. In contrast, $35 \%$ of the HTLV-I-seronegative schistosomiasis control group had degree II, evidence of liver fibrosis that was significant different ( $\mathrm{p}<$ 0.05 , Fisher's exact test) between the two groups.

To evaluate if helminthic infection may influence the immunological response in individuals infected with HTLVI, the levels of IFN- $\gamma$ were evaluated in HTLV-I carriers coinfected with helminthes (S. stercoralis and/or S. mansoni) and patients only infected with HTLV-I without any neurological symptoms (HTLV-I asymptomatic). The levels of IFN- $\gamma$ in supernatants of lymphocyte cultures from HTLV-I carriers with helminthic infection and without helminthic infection are shown in Fig. 4. The IFN- $\gamma$ levels $(1,566$ $\pm 1,662 \mathrm{pg} / \mathrm{ml}$ ) were higher in $35 \mathrm{HTLV}$-I patients without helminthic infection than that observed in 35 patients with 
TABLE

Inverse association between human $\mathrm{T}$ cell leukemia virus-I (HTLV-I) infection and liver fibrosis in patients with schistosomiasis

\begin{tabular}{lcc}
\hline & \multicolumn{2}{c}{ Schistosomiasis groups } \\
\cline { 2 - 3 } $\begin{array}{l}\text { Clinical and } \\
\text { ultrasonography }\end{array}$ & $\begin{array}{c}\text { HTLV-I } \\
\text { co-infected } \\
\text { findings }\end{array}$ & $\begin{array}{c}\text { HTLV-I- } \\
\text { non-infected } \\
(\mathrm{n}=20)\end{array}$ \\
\hline Hepatomegaly & $1 / 22(4.5 \%)$ & $9 / 40(22 \%)^{a}$ \\
Splenomegaly & $0 / 22(0 \%)$ & $1 / 40(2.5 \%)^{a}$ \\
Ultrasound stage I & $21 / 22(95.5 \%)$ & $26 / 40(65 \%)^{a}$ \\
Ultrasound stage II & $1 / 20(4.5 \%)$ & $14 / 40(35 \%)^{a}$ \\
\hline
\end{tabular}

$a: \mathrm{p}<0.05$ (Fisher's exact test)

helminthic infection $(893 \pm 1,174 \mathrm{pg} / \mathrm{ml}, \mathrm{p}<0.05$, MannWhitney U test). Moreover there were less cells expressing IFN- $\gamma$ and more cells expressing IL-10 in HTLV-I patients co-infected with helminths than in individuals only infected with HTLV-I. Fig. 5 shows the frequency of CD8+ T cells secreting IFN- $\gamma$ or IL-10 and the total frequency of cells secreting IL-10 in unstimulated cultures of 4 HTLV-I carriers co-infected with helminths and 7 HTLV-I carriers without co-infection. Co-infection of HTLV-I with helminthes significantly decreases the frequency of CD8 $\mathrm{T}$ cells secreting IFN $-\gamma(\mathrm{p}<0.05)$. In contrast, the total frequency of cells secreting IL-10 and the frequency of CD8+ T cells secreting IL-10 was higher in HTLV-I individuals co-infected with helminthes $(0.58 \%)$ in comparison with these only infected with HTLV-I $(0.21 \%), \mathrm{p}<$ 0.05 .

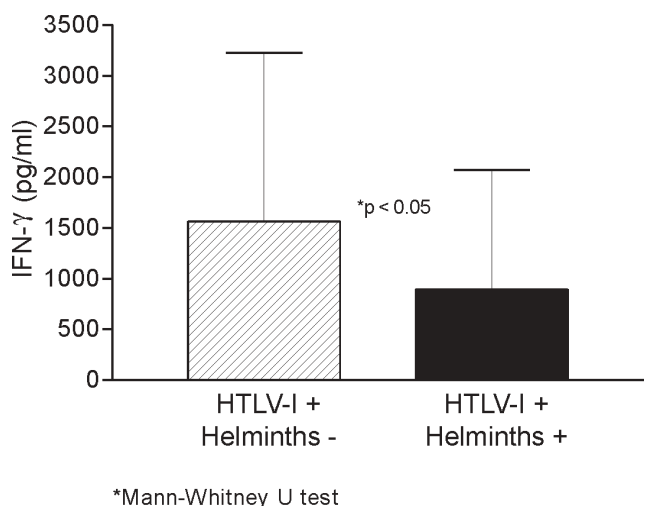

Fig. 4: IFN- $\gamma$ levels of HTLV-I infected patients $(\mathrm{n}=35)$ co-infected or not $(\mathrm{n}=35)$ by helminthes (Strongyloides stercoralis and Schistosoma mansoni).

\section{DISCUSSION}

The present study shows that $S$. mansoni patients co-infected with HTLV-I had their clinical and immunological parameters altered. Co-infection with HTLV-I significantly decreases IL-5 levels, reduces the levels of parasite-specific $\operatorname{IgE}$ and modifies the ultrasonography finding characteristic of infected $S$. mansoni patients. By the other hand, it is also shown that helminthes infections $(S$.

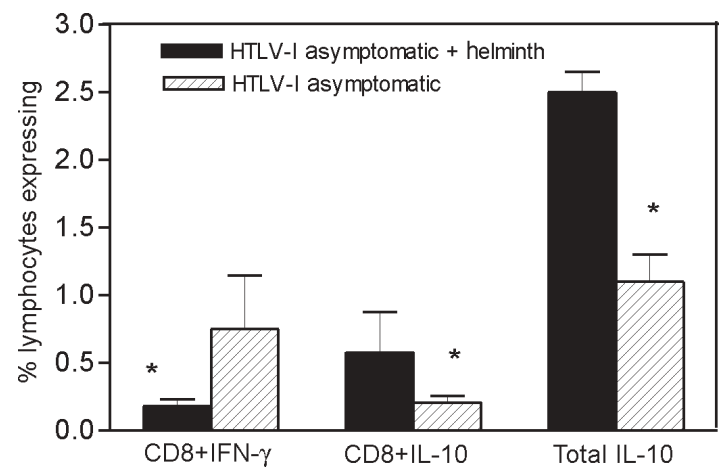

Fig. 5: frequency of CD8+T cell secreting IFN- $\gamma$ or IL-10 in HTLVI carriers co-infected with helmints $(\mathrm{n}=4)$ and HTLV-I carriers without co-infection with helmints $(\mathrm{n}=7)$.

stercoralis and/or S. mansoni) can down modulate the exaggerated inflammatory response observed in HTLV-I infected patients by reducing spontaneous IFN- $\gamma$ synthesis.

The pathogenesis of HAM/TSP is not completely understood. Increased proviral load and the expansion of HTLV-I tax-specific CD8+ cytotoxic T lymphocytes, both in cerebrospinal fluid and in peripheral blood, have been associated with the central nervous system involvement in patients with HAM/TSP (Hanon et al. 2000, Kubota et al. 2000, Nagai \& Jacobson 2001). Moreover, many studies have demonstrated that pro-inflammatory cytokines as IFN- $\gamma$, TNF- $\alpha$, and IL- 15 contribute to tissue damage of the central nervous system of HAM/TSP patients (Umehara et al. 1994, Biddison et al. 1997, Azimi et al. 2000). Additionally, occurrence of fibrosis in neurological tissue was also associated with the immunopathogenesis of the neurological disease associated to HTLV-I (Nagai \& Jacobson 2001). Although the lymphocyte response was quite variable in some HTLV-I asymptomatic carriers, our date indicates a higher and significant IFN- $\gamma$ production in HAM/TSP patients as compared to asymptomatic carriers. Although both type- 1 and type- 2 cytokines are found to increase in unstimulated lymphocyte cultures of HTLVI infected individual when compared with controls (Carvalho et al. 2001), this finding confirm an exacerbated type-1 immune response in these HTLV-I infected subjects

Schistosomiasis is one the most important helminthic disease found in Northeast region of Brazil. Although the majority of patients infected with $S$. mansoni have an intestinal or hepatointestinal form, liver fibrosis is observed in 5\% of patients with long-standing chronic S. mansoni infection. Schistosomiasis is a well-characterized Th2 response-dominated disease (Grzych et al. 1991). Immunological response in chronic schistosomiasis patients is characterized by decreased IFN- $\gamma$ production and enhancement in IL-4, IL-5, and IL-10 levels. This predominant type-2 immune response is independent of the degree of infection measured by egg/stool gram and occurs in all clinical form of schistosomiasis (de Jesus et al. 1993, Araujo et al. 1996). 
High frequency of strongyloidiasis is registered in areas where both HTLV-I and S. stercoralis infection are endemic (Nakada et al. 1984). Additionally, our finding showed that the frequency of $S$. mansoni was increased in HTLV-I infected patients when compared with HTLV-I seronegative controls. Considering that no previous study evaluated the impact of HTLV-I infection on S. mansoni infection, we evaluated the changes in the immune response to $S$. mansoni antigen in co-infected patients. We observed that IL-5, a typical type- 2 cytokine secreted in schistosomiasis, was down regulated in S. mansoni patients co-infected with HTLV-I. In addition, we showed that HTLV-I co-infection decrease the levels of SWAPspecific IgE in S. mansoni infected patients. We have previously shown that HTLV-I decreases antigen specific type-2 immune response in patients with $S$. stercoralis infection (Neva et al. 1998, Porto et al. 2001a). Since there is a tendency for an inverse correlation between IFN- $\gamma$ and IL-5 levels, it is possible that the down regulation of IL-5 and specific-IgE levels is related to the enhancement of type-1 pro-inflammatory cytokines synthesized during HTLV-I infection.

The most severe form of $S$. mansoni infection is the hepatosplenic form. Patients who develop this chronic form show extensive liver fibrosis and hepatosplenomegaly. It is the parasite eggs that, by accumulating in the liver, leading the granuloma formation. Several factors have been associated to liver fibrosis including the genetic background, the degree of infestation and host immunological response. Initially, experimental studies suggested that type- 1 cytokines were associated with granuloma formation (Leptak \& McKerrow 1997, Rezende et al. 1997). However, more recent date point to the importance of type- 2 cytokines such as IL- 4 and IL-13 in inducing fibrosis and the ability of IL-12 and IFN- $\gamma$ to decrease it (Wynn et al. 1994, Chiaramonte et al. 1999b, Jankovic et al. 1999).

HTLV-I infection modifies the immune response to $S$. mansoni antigen. It is possible that the HTLV-I co-infection also modify the clinical manifestation of schistosomiasis in these patients. When ultrasound of $S$. mansoni and HTLV-I co-infected patients were compared with a group of patients having only schistosomiasis but with similar degree of infection than those dually co-infected, the co-infected patients had significant lower liver fibrosis. In such case it is possible that the high type-1 immune response observed by spontaneous IFN- $\gamma$ production in HTLV-I infection or the decrease of type- 2 cytokines are able to preventing the development of fibrosis in coinfected patients.

By the other hand, the evaluation of the role of helminthes infections (S. stercoralis and/or S. mansoni) on the immune response of HTLV-I infected subjects without symptoms showed that co-infection HTLV-I and helminthes had immunological implications. The documentation that IFN- $\gamma$ levels decreased in HTLV-I carriers coinfected with helminthes indicates that helmintic infection may down regulate IFN- $\gamma$ production. It is probably that helminthes down regulate IFN- $\gamma$ production by inducing secretion of IL-10. This date is consistent with the date that show that exogenous IL-10 can decrease IFN- $\gamma$ production in lymphocytes cultures of HTLV-I carriers (Carvalho et al. 2001). Together, these observations suggest that HTLV-I alter the clinical and immunological findings of HTLV-I and S. mansoni co-infection and those HTLV-I individuals co-infected with S. stercoralis and/or $S$. mansoni may decrease IFN- $\gamma$ production and protect HTLV-I carriers to develop diseases associated to HTLVI as HAM/TSP.

\section{ACKNOWLEDGMENT}

To Serviço de Transfusão de Sangue, Salvador, BA and to Hemocentro da Bahia by guiding the blood donors with HTLV positive serology. To Elbe Myrtes Souza Silva for her technical assistance in preparing this manuscript.

\section{REFERENCES}

Abdel-Wahab M F, Esmat G, Farrag A, el-Boraey Y A, Strickland G T 1992. Grading of hepatic schistosomiasis by the use of ultrasonography. Am J Trop Med Hyg 46: 403-408.

Araujo MI, de Jesus AR, Bacellar O, Sabin E, Pearce E, Carvalho EM 1996. Evidence of a T helper type 2 activation in human schistosomiasis. Eur J Immunol 26: 1399-1403.

Azimi N, Mariner J, Jacobson S, Waldmann TA 2000. How does interleukin 15 contribute to the pathogenesis of HTLV type 1-associated myelopathy/tropical spastic paraparesis? AIDS Res Hum Retroviruses 16: 1717-1722.

Biddison WE, Kubota R, Kawanishi T, Taub DD, Cruikshank WW, Center DM, Connor EW, Utz U, Jacobson S 1997. Human T cell leukemia virus type I (HTLV-I)-specific CD8+ CTL clones from patients with HTLV-I-associated neurologic disease secrete proinflammatory cytokines, chemokines, and matrix metalloproteinase. J Immunol 159: 2018-2025.

Bina JC, Prata A 2003. Shistosomiasis in hyperendemic area of Taquarendi: I - Schistosoma mansoni infection and severe clinical forms. Rev Soc Bras Med Trop 36: 211-216.

Carvalho EM, Bacellar O, Porto AF, Braga S, Galvão-Castro B, Neva F 2001. Cytokine profile and immunomodulation in asymptomatic human T-lymphotropic virus type 1-infected blood donors. J Acquir Immune Defic Syndr 27: 1-6.

Chiaramonte MG, Dnaldson DD, Cheever AW, Wynn TA 1999a. An IL-13 inhibitor blocks the development of hepatic fibrosis during a T-helper type 2-dominated inflammatory response. J Clin Invest 104: 777-785.

Chiaramonte MG, Schopf LR, Neben TY, Cheever AW, Donaldson DD, Wynn TA 1999b. IL-13 is a key regulatory cytokine for Th2 cell-mediated pulmonary granuloma formation and IgE responses induced by Schistosoma mansoni eggs. J Immunol 162: 920-930.

de Jesus AM, Almeida RP, Bacellar O, Araujo MI, Demeure C, Bina JC, Dessein AJ, Carvalho EM 1993. Correlation between cell-mediated immunity and degree of infection in subjects living in an endemic area of schistosomiasis. Eur $J$ Immunol 23: 152-158.

de Jesus AR, Miranda DG, Miranda RG, Araujo I, Magalhaes A, Bacellar M, Carvalho EM 2000. Morbidity associated with Schistosoma mansoni infection determined by ultrasound in an endemic area of Brazil, Caatinga do Moura. Am J Trop Med Hyg 63: 1-4.

Edlich RF, Arnette JA,Williams FM 2000. Global epidemic of human T-cell lymphotropic virus type-I (HTLV-I). J Emerg Med 18: 109-119.

Finkelman FD, Shea-Donohue T, Goldhill J, Sullivan CA, Morris SC, Madden KB, Gause WC, Urban Jr JF 1997. Cytokine regulation of host defense against parasitic gastrointestinal nematodes: lessons from studies with rodent models. Annu 
Rev Immunol 15: 505-533.

Grzych JM, Pearce E, Cheever A, Caulada ZA, Caspar P, Heiny S, Lewis F, Sher A 1991. Egg deposition is the major stimulus for the production of Th2 cytokines in murine schistosomiasis mansoni. J Immunol 146: 1322-1327.

Hanon E, Hall S, Taylor GP, Saito M, Davis R, Tanaka Y, Usuku K, Osame M, Weber JN, Bangham CR 2000. Abundant tax protein expression in CD4+ T cells infected with human Tcell lymphotropic virus type I (HTLV-I) is prevented by cytotoxic T lymphocytes. Blood 95: 1386-1392.

Hayashi J, Kishihara Y, Yoshimura E, Furusyo N, Yamaji K, Kawakami Y, Murakami H, Kashiwagi S 1997. Correlation between human $\mathrm{T}$ cell lymphotropic virus type-1 and Strongyloides stercoralis infections and serum immunoglobulin E responses in residents of Okinawa, Japan. Am J Trop Med Hyg 56: 71-75.

Izumo S, Goto I, Itoyama Y, Okajima T, Watanabe S, Kuroda Y, Araki S, Mori M, Nagataki S, Matsukura S, Akamine T, Nakagawa M, Yamamoto I, Osame M 1996. Interferonalpha is effective in HTLV-I-associated myelopathy: a multicenter, randomized, double-blind, controlled trial. Neurology 46: 1016-1021.

Jankovic D, Kullberg MC, Noben-Trauth N, Caspar P, Ward J M, Cheever AW, Paul WE, Sher A 1999. Schistosome-infected IL-4 receptor knockout (KO) mice, in contrast to IL$4 \mathrm{KO}$ mice, fail to develop granulomatous pathology while maintaining the same lymphokine expression profile. $J$ Immunol 163: 337-342.

Kubota R, Kawanishi T, Matsubara H, Manns A, Jacobson S 1998. Demonstration of human T lymphotropic virus type I (HTLV-I) tax-specific CD8+ lymphocytes directly in peripheral blood of HTLV-I-associated myelopathy/tropical spastic paraparesis patients by intracellular cytokine detection. J Immunol 161: 482-488.

Kubota R, Kawanishi T, Matsubara H, Manns A, Jacobson S 2000. HTLV-I specific IFN-gamma+ CD8+ lymphocytes correlate with the proviral load in peripheral blood of infected individuals. J Neuroimmunol 102: 208-215.

Kurtzke JF 1983. Rating neurologic impairment in multiple sclerosis: an expanded disability status scale (EDSS). Neurology 33: 1444-1452.

Leptak CL, McKerrow JH 1997. Schistosome egg granulomas and hepatic expression of TNF-alpha are dependent on immune priming during parasite maturation. J Immunol 158: 301-307.

Nagai M, Jacobson S 2001. Immunopathogenesis of human T cell lymphotropic virus type I-associated myelopathy. Curr Opin Neurol 14: 381-386.

Nakada K, Kohakura M, Komoda H, Hinuma Y 1984. High incidence of HTLV antibody in carriers of Strongyloides stercoralis. Lancet 1: 633.

Neva FA, Filho JO, Gam AA, Thompson R, Freitas V, Melo A, Carvalho E M 1998. Interferon-gamma and interleukin-4 responses in relation to serum IgE levels in persons in- fected with human T lymphotropic virus type I and Strongyloides stercoralis. J Infect Dis 178: 1856-1859.

Newton RC, Limpuangthip P, Greenberg S, Gam A, Neva FA 1992. Strongyloides stercoralis hyperinfection in a carrier of HTLV-I virus with evidence of selective immunosuppression. Am J Med 92: 202-208.

Nishimoto N, Yoshizaki K, Eiraku N, Machigashira K, Tagoh H, Ogata A, Kuritani T, Osame M, Kishimoto T 1990. Elevated levels of interleukin-6 in serum and cerebrospinal fluid of HTLV-I-associated myelopathy/tropical spastic paraparesis. J Neurol Sci 97: 183-193.

Osame M 2002. Pathological mechanisms of human T-cell lymphotropic virus type I-associated myelopathy (HAM/ TSP). J Neurovirol 8: 359-364.

Osame M, Usuku K, Izumo S, Ijichi N, Amitani H, Igata A, Matsumoto M, Tara M 1986. HTLV-I associated myelopathy, a new clinical entity. Lancet 1: 1031-1032.

Phelps KR, Ginsberg SS, Cunningham AW, Tschachler E, Dosik H 1991. Case report: adult T-cell leukemia/lymphoma associated with recurrent strongyloides hyperinfection. Am J Med Sci 302: 224-228.

Porto AF, Neva FA, Bittencourt H, Lisboa W, Thompson R, Alcantara L, Carvalho EM 2001a. HTLV-1 decreases Th2 type of immune response in patients with strongyloidiasis. Parasite Immunol 23: 503-507.

Porto AF, Oliveira Filho J, Neva FA, Orge G, Alcantara L, Gam A, Carvalho EM 2001b. Influence of human T-cell lymphocytotropic virus type 1 infection on serologic and skin tests for strongyloidiasis. Am J Trop Med Hyg 65: 610613.

Rezende SA, Lambertucci JR, Goes AM 1997. Role of immune complexes from patients with different clinical forms of schistosomiasis in the modulation of in vitro granuloma research. Mem Inst Oswaldo Cruz 92: 683-687.

Robinson RD, Lindo JF, Neva FA, Gam AA, Vogel P, Terry SI, Cooper ES 1994. Immunoepidemiologic studies of Strongyloides stercoralis and human T lymphotropic virus type I infections in Jamaica. J Infect Dis 169: 692-696.

Souza-Atta ML, Araujo MI, D'Oliveira Junior A, Ribeiro-deJesus A, Almeida RP, Atta AM, Carvalho EM 1999. Detection of specific IgE antibodies in parasite diseases. Braz $J$ Med Biol Res 32: 1101-1105.

Uchiyama T 1997. Human T cell leukemia virus type I (HTLVI) and human diseases. Annu Rev Immunol 15, 15-37.

Umehara F, Izumo S, Ronquillo AT, Matsumuro K, Sato E, Osame M 1994. Cytokine expression in the spinal cord lesions in HTLV-I-associated myelopathy. J Neuropathol Exp Neurol 53: 72-77.

Wynn TA, Eltoum I, Oswald IP, Cheever AW, Sher A 1994. Endogenous interleukin 12 (IL-12) regulates granuloma formation induced by eggs of Schistosoma mansoni and exogenous IL-12 both inhibits and prophylactically immunizes against egg pathology. J Exp Med 179: 1551-1561. 